\title{
Hepatitis C - What does the future hold?
}

\author{
VG Bain MD
}

W ithout question, hepatitis $\mathrm{C}$ was the liver disease of the 1990s. New cases continue to emerge at an alarming rate, yet most patients have been infected for many years. Rapid advances have been made in understanding the biology of this virus and its natural history, and, furthermore, effective antiviral therapy has become available (1). Nevertheless, infected patients will slowly progress, leading to many more patients with advanced liver disease. How many cases are there likely to be? How many of these cases will require liver transplantation? For the first time, there are $\mathrm{Ca}$ nadian data to address these questions.

As presented in this issue of The Canadian Journal of Gastroenterology, Zou and colleagues (pages 575-580) used available information to calculate the current (1998) and 10-year hepatitis $\mathrm{C}$ burden. They used a previously published estimate of hepatitis $\mathrm{C}$ prevalence in Canada (2), then calculated the distribution of cases by age and the likely time of infection. A natural history model (Schering Plough Pharmaco Economic Analysis Review System [SPEARS]) was used to determine to which stage of disease these cases would progress over the next 10 years. If individuals who are newly infected from 1998 to 2008 are ignored, the calculated increases in patients with important disease-related outcomes are very large. Cases of hepatitis C-induced cirrhosis will increase by $92 \%$, decompensated cirrhosis by $126 \%$, patients requiring liver transplantation by $246 \%$ (assuming donor availability) and hepatocellular carcinoma by $102 \%$.

Are we ready to meet this burden of disease? Quite simply - no! Most current cases are still undiagnosed. Those who are diagnosed are usually referred to infectious disease, gastroenterology or hepatology specialists for assessment. Despite an increased number of hepatologists countrywide, many patients wait six to 12 months to be assessed. The gold standard for treatment is the combination of alpha-interferon and ribavirin for 24 to 48 weeks. It is an intensive and expensive treatment, and requires careful laboratory monitoring. Almost all provinces have viral load and genotype testing available, which allows the optimum duration of therapy to be determined. Specialist hepatitis nurses have been trained and hired across the country to assist treating physicians. Most health regions have not yet appreciated this need; therefore, most of these now highly skilled and experienced nurses are supported by the pharmaceutical industry.

By using the combination of alpha-interferon and ribavirin antiviral therapy, up to $40 \%$ of patients have a sustained response $(3,4)$, defined as the absence of hepatitis $\mathrm{C}$ virus RNA in the serum by a sensitive qualitative assay six months after treatment has finished. This appears to be an excellent surrogate marker for long term and possibly permanent viral clearance (5) as well as for marked histological improvement $(3,4)$. Over and above the patients who achieve a sustained response, another approximately $25 \%$ have histological improvement $(3,4)$. In nonresponders, this histological improvement is likely to be short lived after treatment is stopped and is probably unimportant in a disease with a natural history measured in decades. Virological responses are likely to be further improved by the use of long acting pegylated interferon in combination with ribavirin. Pegylated interferon is now in clinical trials. To meet tomorrow's challenges, more physicians need to be trained to treat chronic hepatitis C. Ongoing research will better define the natural history and burden of disease, as predicted by studies such as that by Zou and colleagues in this issue. Attention to viral kinetics will allow earlier and more precise assessments and 
changes of treatment. New antivirals with novel targets will permit new multidrug regimens that will be essential for the successful treatment of such a mutable virus. Predictably, this field will become more complex as ways to eradicate dif-

\section{REFERENCES}

1. Keeffe EB, ed. Clinics in Liver Disease, vol 3. Philadelphia: WB Saunders Company, 1999

2. Ramis R, Hogg R, Krahn MD, Preiksaitis JK, Sherman M. Estimating the number of blood transfusion recipients infected by hepatitis $\mathrm{C}$ virus in Canada, 1960-85, and 1990-92. Ottawa: Health Canada, June 1998.

3. Poynard T, Marcellin P, Lee S, et al. Randomized trial of interferon alpha $2 \mathrm{~B}$ plus ribavirin for 48 weeks or for 24 weeks versus interferon ferent types of resistant viruses are discovered. However, it is only by early successful treatment that cirrhosis, hepatocellular carcinoma and the need for liver transplantation can be prevented.

alpha 2B plus placebo for 48 weeks for treatment of chronic infection with hepatitis $\mathrm{C}$ virus. Lancet 1998;352:1426-32.

4. McHutchison JG, Gordon SC, Schiff ER, et al. Interferon alfa-2b alone or in combination with ribavirin as initial treatment for chronic hepatitis C. N Engl J Med 1998;339:1485-92.

5. Davis G, McHutchison J, Poynard T, et al. Durability of viral response to interferon alone or in combination with oral ribavirin in patients with chronic hepatitis C. Hepatology 1999;30:330A. (Abst) 


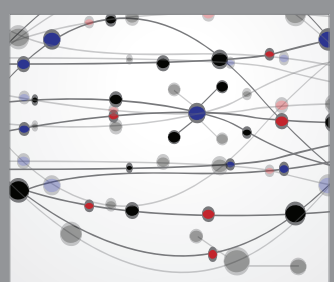

The Scientific World Journal
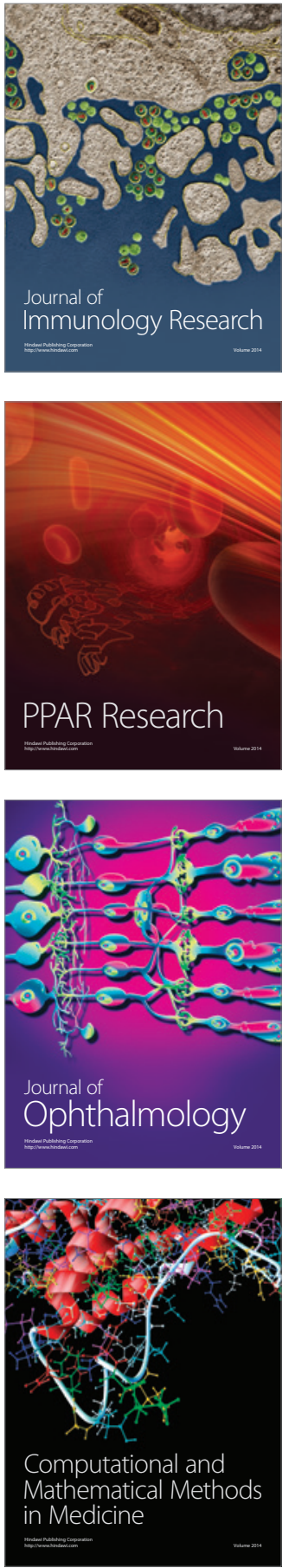

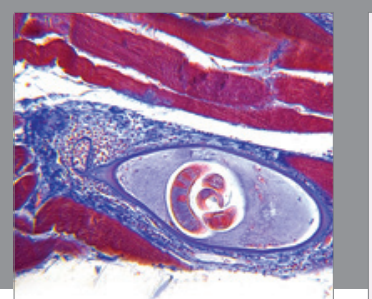

Gastroenterology Research and Practice

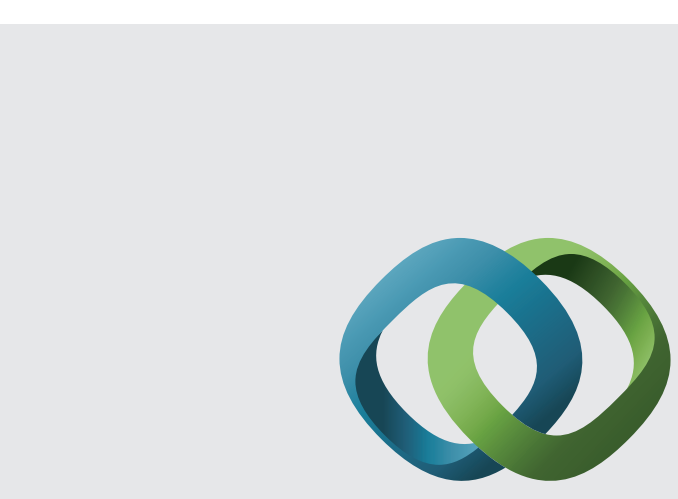

\section{Hindawi}

Submit your manuscripts at

http://www.hindawi.com
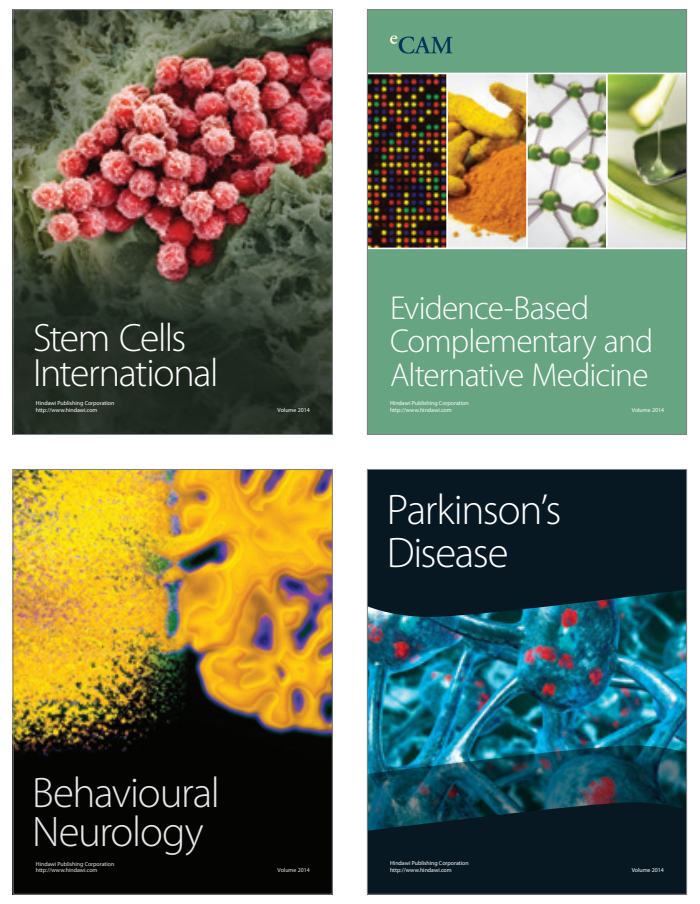
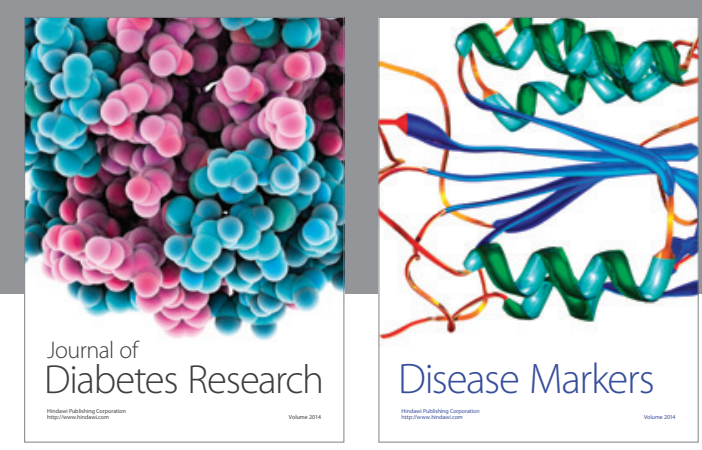

Disease Markers
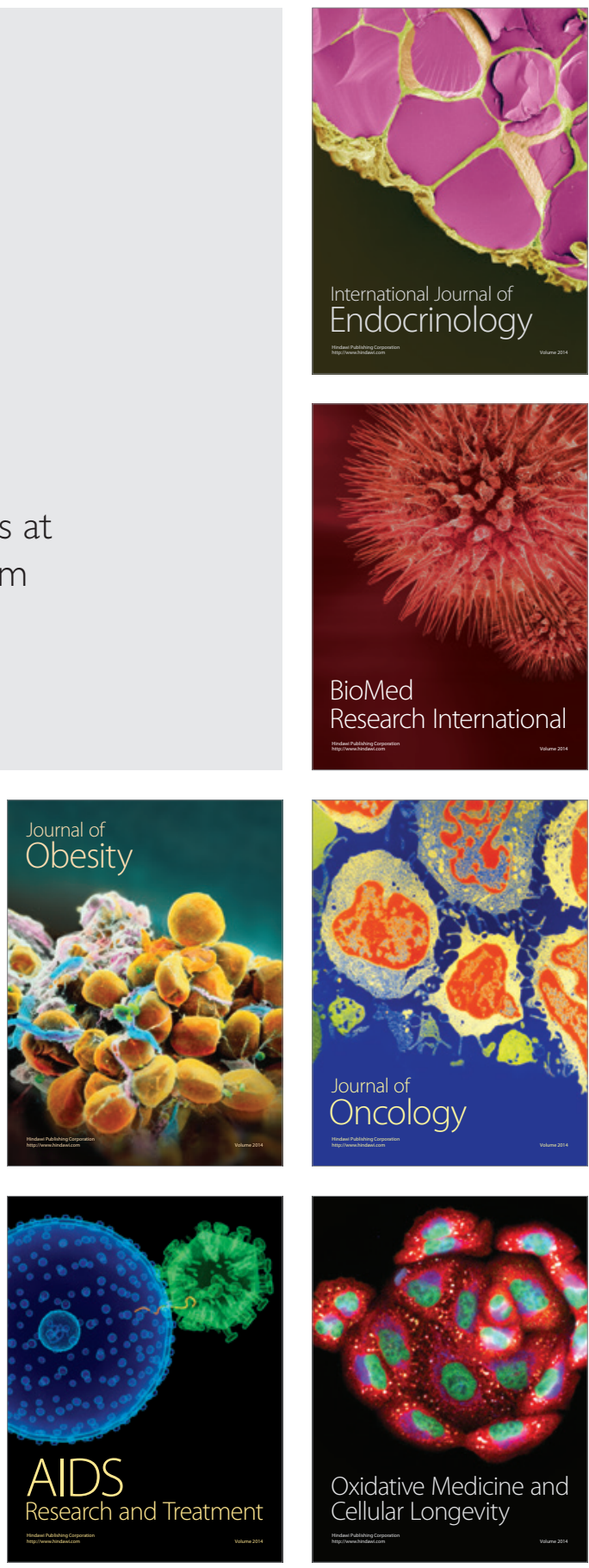